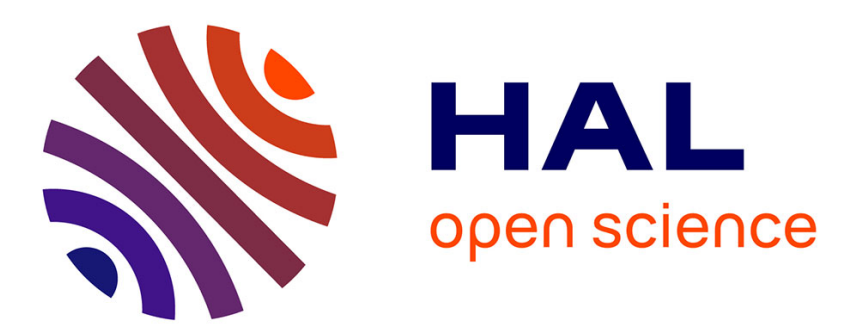

\title{
Tone Noise Predictions of a Full-Scale UHBR Engine at Approach Condition with Inflow Distortion Effects
}

Thomas Le Garrec, Cyril Polacsek, Alain Chelius, Majd Daroukh, Benjamin François

\section{- To cite this version: \\ Thomas Le Garrec, Cyril Polacsek, Alain Chelius, Majd Daroukh, Benjamin François. Tone Noise Predictions of a Full-Scale UHBR Engine at Approach Condition with Inflow Distortion Effects. 25th AIAA/CEAS Aeroacoustics Conference, May 2019, DELFT, Netherlands. hal-02196612}

\section{HAL Id: hal-02196612 \\ https://hal.science/hal-02196612}

Submitted on 29 Jul 2019

HAL is a multi-disciplinary open access archive for the deposit and dissemination of scientific research documents, whether they are published or not. The documents may come from teaching and research institutions in France or abroad, or from public or private research centers.
L'archive ouverte pluridisciplinaire HAL, est destinée au dépôt et à la diffusion de documents scientifiques de niveau recherche, publiés ou non, émanant des établissements d'enseignement et de recherche français ou étrangers, des laboratoires publics ou privés. 


\title{
Tone Noise Predictions of a Full-Scale UHBR Engine at Approach Condition with Inflow Distortion Effects
}

\author{
T. Le Garrec, ${ }^{1}$ C. Polacsek ${ }^{2}$, A. Chelius ${ }^{3}$, M. Daroukh ${ }^{4}$, \\ ONERA -The French Aerospace Lab, F-92322, Châtillon Cedex, France \\ B. François ${ }^{5}$ \\ ONERA -The French Aerospace Lab, F-92190, Meudon, France
}

\begin{abstract}
Modern UHBR (Ultra High Bypass Ratio) aeroengines are characterized by reduced fan speeds and very short asymmetric intakes, so that the mean flow entering into the nacelle is no more uniform along the azimuthal direction (particularly at operating conditions with non-zero angle of attack). Such short inlets and inflow distortions can highly modify the dominant tone noise contributions known from conventional turbofans. This paper presents aeroacoustic investigations applied to a full scale UHBR engine in the framework of the CleanSky2 European project, ASPIRE. Numerical simulations based on (u)RANS calculations are coupled to integral formulations derived from the Ffowcs-Williams and Hawkings analogy and to CAA (Computational AeroAcoustics) based on non-linear disturbance Euler equations, in order to assess the source generation and sound propagation of the fan-OGV stage with and without inflow distortion. Simulations are performed at approach operating condition and CAA is focused on the intake region and forward radiation. It is shown that the inflow distortion effects significantly modify the harmonic loads (on rotor and stator) and so the associated circumferential mode spectrum. Although the blade passing frequency remains cut-off, these effects give rise to an increase of overall power level in the forward direction, and a non expected reduction in the bypass duct too.
\end{abstract}

\section{Introduction}

Modern UHBR (Ultra High Bypass Ratio) aeroengines are characterized by reduced fan speeds and very short asymmetric intakes, so that the mean flow entering into the nacelle is no more uniform along the azimuthal direction. This heterogeneity of the entering flow in short intakes is amplified at OP (Operating Point) conditions with non-zero AoA (Angle of Attack), typically for AoA $=10-15^{\circ}$ for which the inflow direction is not aligned with the axis of the nacelle. As shown by recent studies [1][2][3][4][5], such inflow distortions can highly modify the tone noise characteristics known from conventional turbofans. This paper presents aeroacoustic investigations performed by ONERA on a full-scale UHBR engine in the framework of the CleanSky2 European project, ASPIRE, in collaboration with NLR, DLR, and Airbus. A brief description of ONERA methodologies and preliminary results obtained on the baseline case (without distortion) have been discussed in a previous communication [6], related to a subsonic and a transonic configurations. Present work and analyses are extended to the distortion case and focused on the approach OP for which a CFD/CAA coupling has been proposed using respective ONERA's solvers elsA [7] and sAbrinA [8][11]. The CAA code, solving the non-linearized Euler equations (applied to the disturbances) in the time domain, allows to simulate the full 3D geometry and to take into account non-uniform convection flow (with asymmetric inflow) in the acoustic propagation, that are both approximated when using current FWH (FfowcsWilliams and Hawkings) analogy adapted by Goldstein [12] as used in Refs. [6][13], and adopting annular duct/uniform mean flow assumptions.

Different approaches are proposed here to capture the dominant source mechanisms and to assess the tone noise propagation and radiation by the inlet. CFD simulations, based on uRANS calculations, are performed by using the

\footnotetext{
${ }^{1}$ Research Engineer, Department of Aerodynamics, Aeroelasticity, and Acoustics, thomas.le_garrec@onera.fr.

2 Research Engineer, Department of Aerodynamics, Aeroelasticity, and Acoustics, cyril.polacsek@onera.fr.

${ }^{3}$ Research Engineer, Department of Aerodynamics, Aeroelasticity, and Acoustics, alain.chelius@onera.fr.

${ }^{4}$ Research Engineer, Department of Aerodynamics, Aeroelasticity, and Acoustics, majd.daroukh@onera.fr.

5 Research Engineer, Department of Aerodynamics, Aeroelasticity, and Acoustics, benjamin.francois@onera.fr.
} 
finite volume solver elsA [7], particularly devoted to turbomachinery applications, and aiming to provide the main acoustic sources, i.e., rotor and stator unsteady loads, and also the disturbance field upstream of the fan required for the CAA. For axisymmetric configurations, uRANS computation domains are limited to a single inter-blade channel by applying chorochronicity conditions, whereas $360^{\circ}$ simulations are required in the presence of inflow distortion. Both CFD calculations are restricted to the internal flow of the fan/OGV stage and an inflow distortion map issued from another uRANS solution provided by NLR [14] is used as a specific boundary condition in elsA. The harmonic loadings issued from chorochronic or $360^{\circ} \mathrm{CFD}$ solutions are used as inputs to an in-house code FanNoise solving the Goldstein's formulation and providing the in-duct sound field, in terms of SPL (Sound Pressure Level) and PWL (PoWer Level) spectra. The radiated field from the intake can be also estimated by means of a Kirchhoff formulation written in a modal form [15][16] and entering the Fourier-Bessel mode amplitudes over the inlet section (provided by FanNoise) as inputs. Such a modelling is relevant for clean inflow and is applied to the baseline case. In order to achieve more accurate predictions, the CFD is chained to the CAA solver (sAbrinA) through a so-called NRI (NonReflective Interfacing) method [17][18]. This CFD/CAA coupling is only applied to the more complex configuration in the presence of inflow distortion, and the full numerical predictions are compared to the URANS+FWH solutions (assessed for baseline and distortion cases).

The turbofan model designed in ASPIRE project has an asymmetric intake due to a small drop, but to make the use of chorochronic technique possible and to save computational efforts, the drop is neglected in our CFD simulations, that are performed with an axisymmetric nacelle assumption. However, the actual dropped intake is taken into account when prescribing the inflow distortion map, and in the CAA for which the full annular nacelle is meshed.

The final paper, that will be a bit more detailed than the present extended abstract, is structured as follows:

- Section II gives basic information about ASPIRE turbofan model and operating conditions;

- Section III describes the hybrid methods considered in this study: the CFD (uRANS) part, the CFD post-processing with respect to acoustic analogies, and the CAA part involving CFD/CAA coupling strategy;

- Section IV presents the main results achieved, featuring relevant unsteady aerodynamics, in-duct acoustic field assessments with attention paid to modal contents, near-field and far-field radiation from the intake, and sound power balance, aiming to highlight the main distortion effects by comparison to the baseline case;

- Finally, some conclusions and perspectives are addressed in Section V.

\section{Turbofan configuration and application case}

The ASPIRE fan stage has a cut-off design for the $\mathrm{BPF}_{1}$ (Blade Passing Frequency) with $B=16$ rotor blades and $V=36$ OGV's. The target bypass ratio is equal to 16 and the in-flight minimum thrust was chosen to be representative of a modern mid-sized passenger aircraft, with a nacelle radius around 1 meter. The main turbofan characteristics and operating conditions for the approach case are summarized in the Table 1.

Table 1 Turbofan characteristics and operating conditions w/wo distortion flow

\begin{tabular}{|c|c|}
\hline Blade number, $B$ & 16 \\
\hline Vane number, $V$ & 36 \\
\hline Bypass ratio & 16 \\
\hline $\begin{array}{c}\text { Fan rotation speed (\%) } \\
\text { (Vs. nominal regime) }\end{array}$ & $56 \%$ \\
\hline Flight Mach number, $M$ & 0.23 \\
\hline Relative tip Mach number, $M_{\text {tip }}$ & 0.55 \\
\hline Angle of attack (deg.), AoA & $0^{\circ}$ (baseline) or $10^{\circ}$ (distortion) \\
\hline
\end{tabular}




\section{Hybrid methodologies}

\section{A. CFD part description}

Two different strategies have been carried out for the baseline and distortion configurations. For axisymmetric configurations, such as the baseline case, uRANS computation domains are limited to a single inter-blade channel by applying chorochronicity conditions, whereas $360^{\circ}$ simulations are required in the presence of inflow distortion. Both CFD calculations performed with ONERA elsA code [7] are restricted to the internal flow of the fan/OGV stage and an inflow distortion map issued from another uRANS solution provided by NLR [14] is used as a specific boundary condition in elsA.

The CFD domain considered for uRANS computations in the baseline configuration and a section view of the mesh are red colored in Fig. 1, left and right, respectively. The single channel grid (about 10 million points) is designed to convect the rotor wakes up to the OGV accurately and a stretching is added in the upstream and downstream directions to limit numerical reflections at inlet and outlet boundaries. A RANS mixing plane approach is first applied to initialize the uRANS simulations performed using k-epsilon turbulence model and 2nd-order Roe spatial scheme with Van Albada limiter. Unsteady part of the simulation is then realized by switching from RANS mixing plane to uRANS with chorochronicity conditions. Both steady and unsteady time integrations are based on a 1st-order backward Euler scheme.
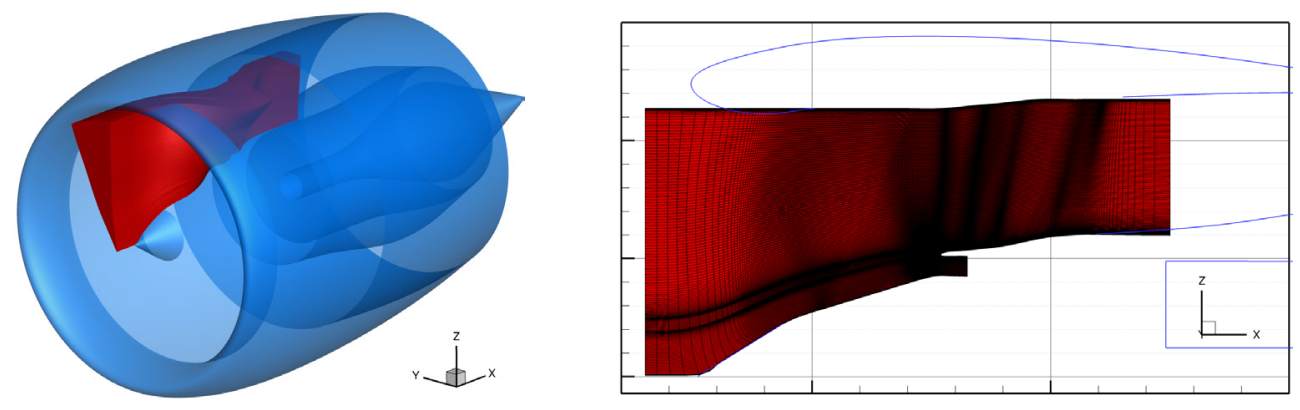

Fig. 1 Baseline configuration: computational domain (in red, left) and grid section view (right).

The distortion case simulation is computed by performing a uRANS $360^{\circ}$ calculation (approach $\mathrm{OP}, \mathrm{AoA}=10^{\circ}$ ) still using a full annulus geometry with axisymmetric inlet approximation. The requested inflow distortion map has been provided by NLR [14] and enforced in the CFD as a suited inlet boundary condition (blue disk in Fig. 2 right). The distortion map is located at $-0.35 \mathrm{~m}$ from the fan plane (see Fig. 2, left) and then interpolated onto the $360^{\circ} \mathrm{CFD}$ grid (Fig. 2, middle). In practice, the $360^{\circ}$ grid totalizes about 182 million points, and is deduced from the previous one (baseline) by shortening the inlet boundary up to the distortion plane and a no-match sliding grid technique is used at each interface between fixed and rotating domains (see brown and green discs upstream and downstream of the fan in Fig. 2, right). Due to the short inlet, this approach is quite challenging as the distortion map plane is very close from the fan so that spurious coupling effects might occur.

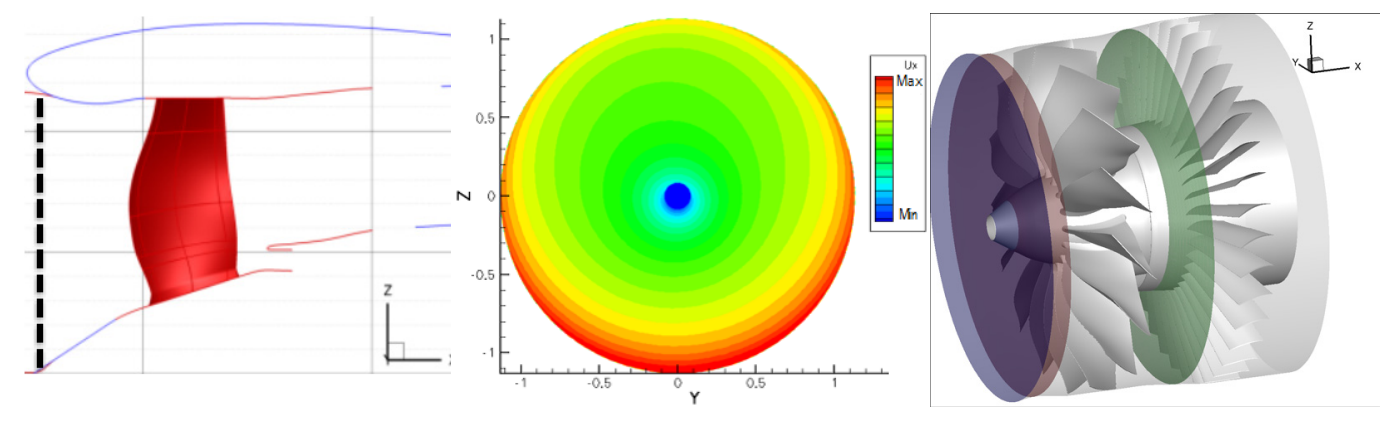

Fig. 2 Distortion map position (left), axial velocity map (middle), and $360^{\circ}$ dist./fan/OGV set-up (right). 
Two types of acoustic post-processing have been applied to the present CFD simulations:

- CFD post-processing using acoustic analogies on both configurations,

- CFD/CAA coupling strategy only on the distortion case.

Main extracted CFD data required by the first one are the harmonic loadings of unsteady surface pressure on a single fan blade (over a full revolution for the distortion case) and on each of 36 stator vanes (over a single blade passage). For the second, the Fourier transform of the primitives variables are extracted on a disk of small thickness placed inbetween the no-match sliding disk and the leading edge of the fan blades.

\section{B. CFD post-processing using acoustic analogies}

The harmonic loadings issued from chorochronic or $360^{\circ} \mathrm{CFD}$ solutions are used as inputs to an in-house code FanNoise solving the Goldstein's formulation and providing the in-duct sound field, in terms of SPL (Sound Pressure Level) and PWL (PoWer Level) spectra due to rotor and stator sources contribution. Main assumptions are a uniform and axial convection flow, a fully annular geometry, and no screen effects (sound scattering by rotor or stator neglected). The acoustic field is classically expanded over angular $(m)$ and radial $(\mu)$ modes following Eq. 1, and the calculations are restricted to the well-known Tyler \& Sofrin modes [19]: $m=n B-k V$.

$$
p_{m \mu}^{ \pm}(x, r, \theta, f)=A_{m \mu}^{ \pm}(f) \Psi_{m \mu}(r) e^{-i\left(m \theta+k_{m \mu}^{ \pm} x\right)}
$$

The radiated field from the intake can be also estimated by means of a Kirchhoff formulation written in a modal form [15][16] and entering the Fourier-Bessel mode amplitudes over the inlet section (provided by FanNoise) as inputs. Such a modelling is relevant for clean inflow and is applied to the baseline case.

In the presence of inflow distortion, in addition to the fan-OGV interactions (periodic rotor-blade wakes impacting the stator vanes and rotor blades crossing the OGV potential field), unsteady loads on the rotor blades crossing the heterogeneous inflow are generating additional Tyler and Sofrin cut-on modes of order $m=n B-k$, where $k$ is the harmonic order of the angular Fourier transform of the distorted velocity field. All these mechanisms are included in FanNoise calculations. Furthermore, most energetic evanescent modes at cut-off BPF $_{1}$ are also taken into account for the upstream propagation of rotor sources.

\section{CFD/CAA coupling strategy and numerical set-up}

The previous modelling based on Goldstein's formulation is very relevant for clean inflow and is applied to the baseline case. It is also applied to the distortion case, even though some hypotheses are not strictly respected. In order to achieve more accurate acoustical predictions, the $360^{\circ} \mathrm{CFD}$ is chained to the CAA solver (sAbrinA) through a so-called NRI (Non-Reflective Interfacing) method [17][18]. This CFD/CAA coupling is only applied to the more complex configuration in the presence of inflow distortion, and the full numerical predictions are compared to the uRANS+FWH solutions (assessed for baseline and distortion cases).

The NRI technique [17][18] implemented in the NLDEE (Non Linear Disturbance Euler Equation) time-domain solver sAbrinA is applied for the first time to a UHBR turbofan. sAbrinA is a structured grid, time-accurate CAA code that solves either the full or the linear Euler equations, in a conservative and perturbed form (with a splitting of the complete variables into a "frozen" mean flow and a "fluctuating" perturbation). The solver employs high-order, finite difference operators, involving 6th-order spatial derivatives and 10th-order filters, as well as a 3rd-order, multi-stage, Runge-Kutta time-marching scheme. The code deals with multi-block structured grids with one-to-one interfaces, and is fully parallelized using the Message Passing Interface (MPI) standard. Finally, the solver includes the usual boundary conditions (reflection by solid walls, non-reflecting / free-field radiation [8], etc.), as well as some unique to specific applications (such as the surface coupling technique [17][18]). More detailed information about the sAbrinA solver and its underlying methodology can be found in [9][10].

This method aims to accurately capture the main harmonic sources and to simulate the sound propagation taking into account the actual geometry and convection effects through a non-linearized Euler solver. The CFD/CAA coupling is achieved using the uRANS disturbance field solution Steady mean flow in the vicinity of the intake (internal and external flow) to be used as convection flow in sAbrinA, has been kindly provided by NLR since a full annulus geometry is considered in the ONERA uRANS calculation. Hence, a few interpolations (using in-house Python/Cassiopée tool [21]) are required to transfer the CFD solutions, obtained on different meshes, to the CAA grid. One of the main difficulties of the present CFD/CAA strategy is that the mean flow used in the CAA has to be specified into a fixed frame (linked to the nacelle), without the presence of the fan blades, whereas the uRANS 
calculation is partly performed in a rotating frame (linked to the fan). A simple time averaging of unsteady solution extracted from the rotating frame (as done by NLR) cannot be used directly and tricky smoothing processes are applied to remove the potential field contributions around each fan blade sector while preserving the inhomogeneous $360^{\circ}$ field. Moreover, a time-Fourier transform is applied to the uRANS data within the NRI volume (practically 11 layers are stored) in order to inject directly the non-conservative variables in the form of prescribed harmonics $\left(\mathrm{BPF}_{1}\right.$ to $\mathrm{BPF}_{5}$ here).

The CAA $360^{\circ}$ calculation provides the sound pressure radiated by the $3 \mathrm{D}$ intake in the near-field area corresponding to the refined region of the grid, and this direct solution is extrapolated to the far field by means of a Kirchhoff integral (performed in the frequency domain too). The $360^{\circ}$ CAA domain and cut view of the CAA grid in (XZ) plane are shown in Fig. 3. The refined region is extending up to 2 radii beyond the exit plane in the axial direction and up to \pm 2 radii in the radial direction, with a grid density ensuring at least 15 points per wavelength at $\mathrm{BPF}_{3}$. The mesh is fully structured and contains 4 blocks with a polar shape, with about 48 millions points. It supports frequencies up to $\mathrm{BPF}_{3}$ with 15 pts. per wavelength. These tones are accurately supported in the region delimited by the pink rectangle in Fig. 3 right, and frequencies lower than $\mathrm{BPF}_{3}$ will propagate a little bit further before being dissipated by the grid size stretching with a ratio between 1,03 and 1,05. The azimuthal direction is discretized by 600 points which gives $600 / 16=37.5$ points per blade sector. Furthermore, the spinner geometry has been slightly modified due to the mean flow availability and feasibility. The CFL number has been set to 0.8 , which provides a time step of $\Delta \mathrm{t} \approx 4.510^{-7} \mathrm{sec}$. One complete revolution of the fan requires about $10^{5}$ temporal iterations. The simulation is run during three complete revolutions in order to evacuate the numerical transient (2 revolutions) and to compute converged statistics ( 1 revolution). The retrieval time is about $200 \mathrm{~h}$ on 408 processors. The $\mathrm{CFD} / \mathrm{CAA}$ coupling is based on the injection of the primitive (non-conservative) perturbed variables (density, pressure and velocity) over a NRI volume made of 11 adjacent layers taken from the CAA mesh.
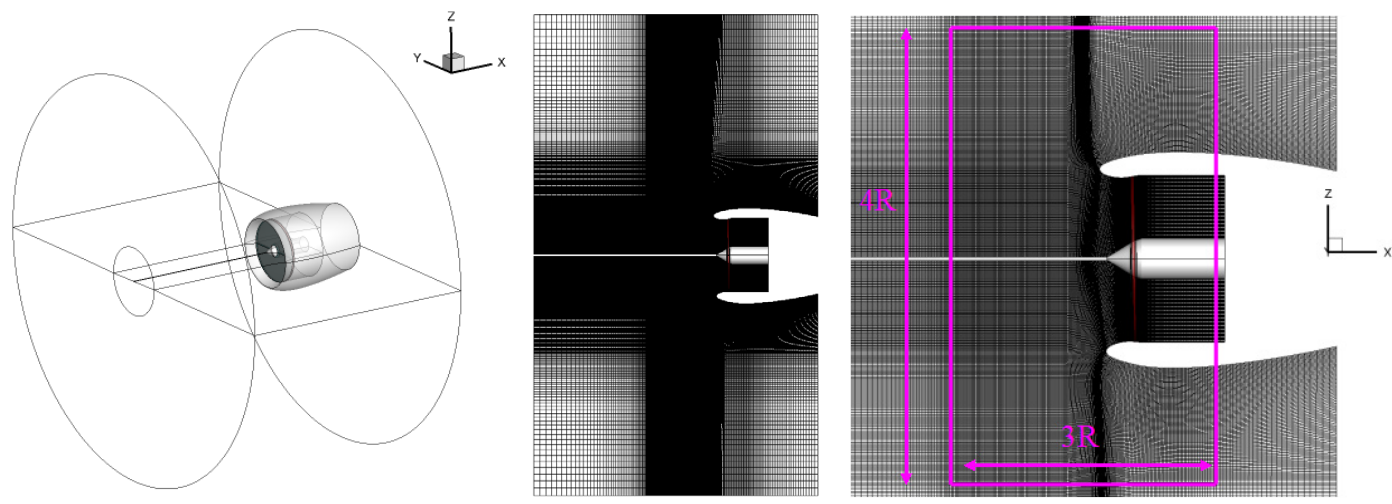

Fig. $3360^{\circ}$ CAA domain (left) with $\mathrm{XZ}$ cut view of CAA grid (middle) and zoom of the refined region (right).

As illustrated in Fig. 4, this volume has to be located in the CFD region comprised between the distortion and fan planes with a suitable mesh density and discarding axial cuts crossing the blade skin. Due to the very short inlet, the coupling zone extent is quite limited. Practically, the NRI volume with CAA layers are prescribed in the CFD and the output data are extracted and interpolated onto this volume. Then a time-Fourier transform is applied before injecting the primitive variables in the CAA. Real part of pressure harmonics $(\mathrm{Pa})$ over NRI section for $\mathrm{BPF}_{1}-\mathrm{BPF}_{3}$ is depicted in Fig. 5 with a view from the intake. Effects of the distortion are clearly noticeable with asymmetric patterns at all frequencies. 

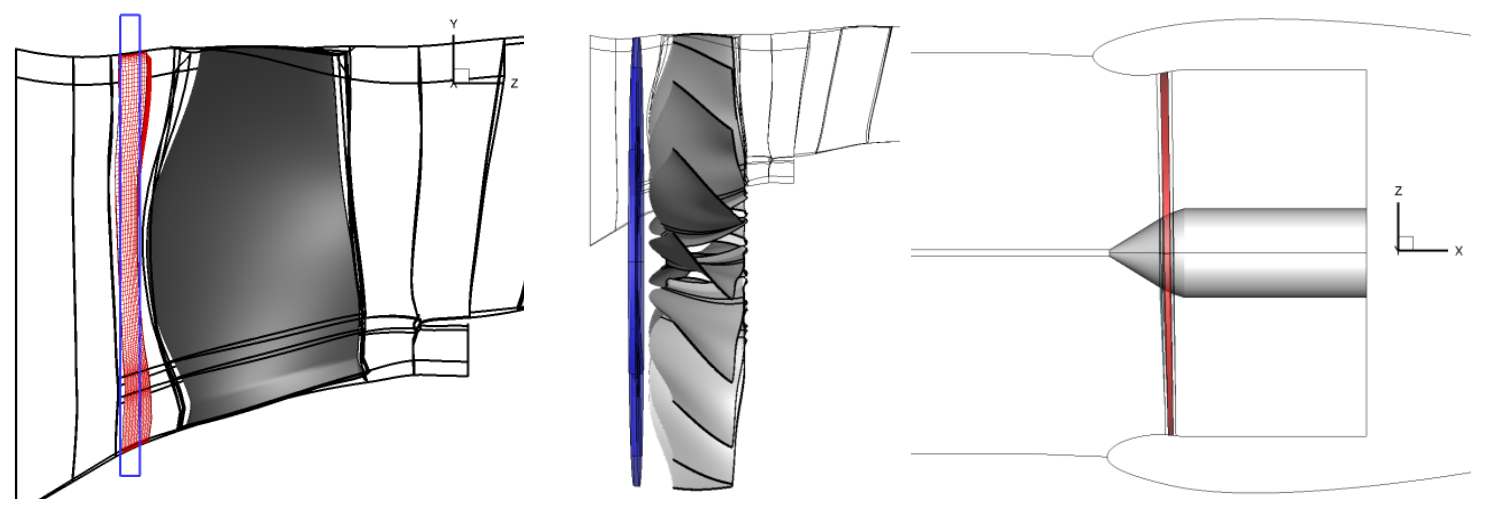

Fig. 4 Coupling zone in the CFD (left) with NRI volume (middle), and transfer to the CAA grid (right).
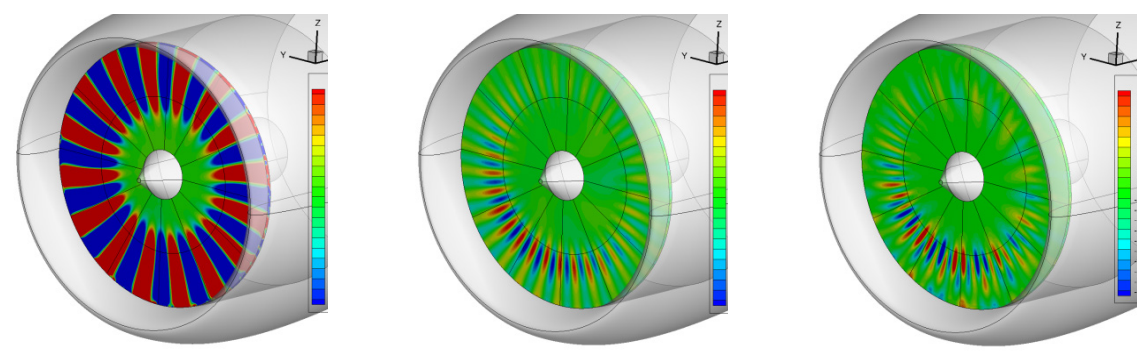

Fig. 5 Real part of pressure harmonics (Pa) over NRI section at $\mathrm{BPF}_{1}$ (left), $\mathrm{BPF}_{2}$ (middle) and $\mathrm{BPF}_{3}$ (right).

As mentioned before, another difficulty of the method is the assessment of a reliable mean flow in the fixed frame to be used as convection flow in our NLDEE solver. For that purpose, we use ONERA RANS mixing plane solution (Fig. 6, left) for internal region up to the distortion plane, and NLR solution (Fig. 6, middle) in the external region of the nacelle and internal region between the intake exit and the distortion plane. As observed in Fig. 6 (middle), the time-averaged uRANS solution provided by NLR exhibits discontinuities at the interfaces between rotating and fixed computation domains. Typical final solution prescribed in the CAA after applying a few smoothing processes is shown in Fig. 6, right. Inside the nacelle, the mean flow solution in the CAA is simply extruded from the NRI volume up to the outflow boundary condition, assuming a fully annular geometry. This approximation should have a negligible impact on the upstream propagation and radiation by the intake.

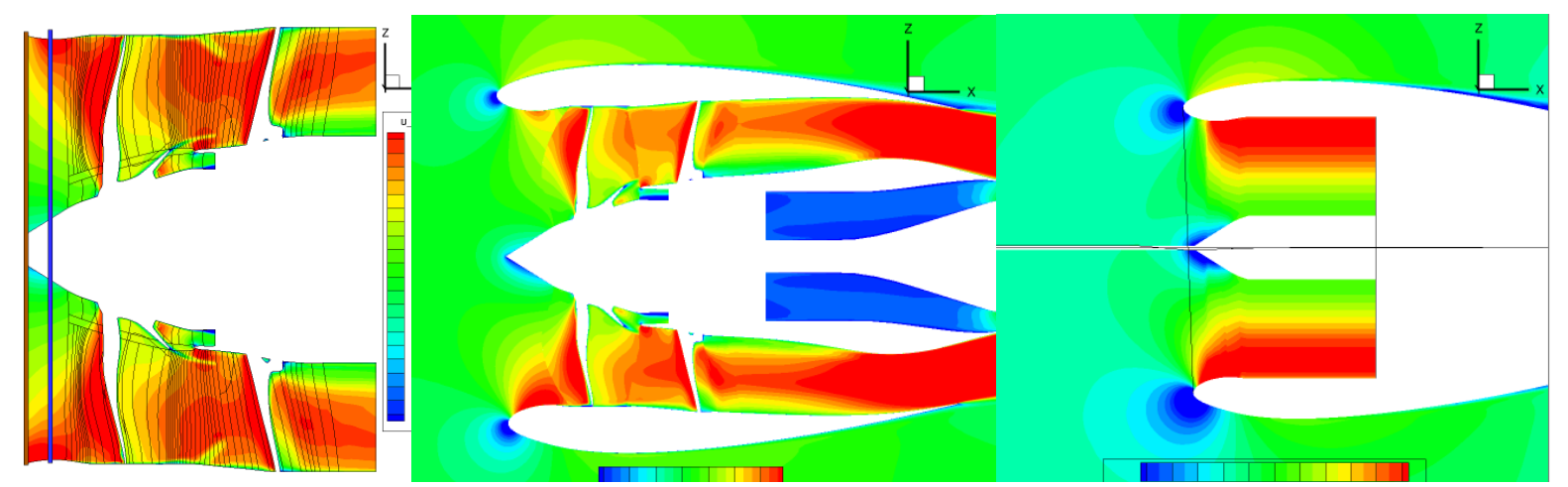

Fig. 6 Mean flow solutions of axial velocity field from both CFD calculations to CAA - ONERA RANS mixing plane (left), NLR time-averaged uRANS (middle) and final CAA convection flow (right).

Finally, these direct solutions have been extrapolated to the far field by using a Kirchhoff integral (the adoption of a porous FWH formulation, also implemented in ONERA solvers, is not useful when focusing on forward radiation). The definition of integration surface is shown in Fig. 7 left (orange color) and the observer surface used 
for spherical mapping at $\mathrm{r}=100 \mathrm{~m}$ is plotted in Fig. 7 right (a 20 factor is applied to the nacelle geometry scale). Porous surfaces are included inside the refined zone of the CAA mesh.
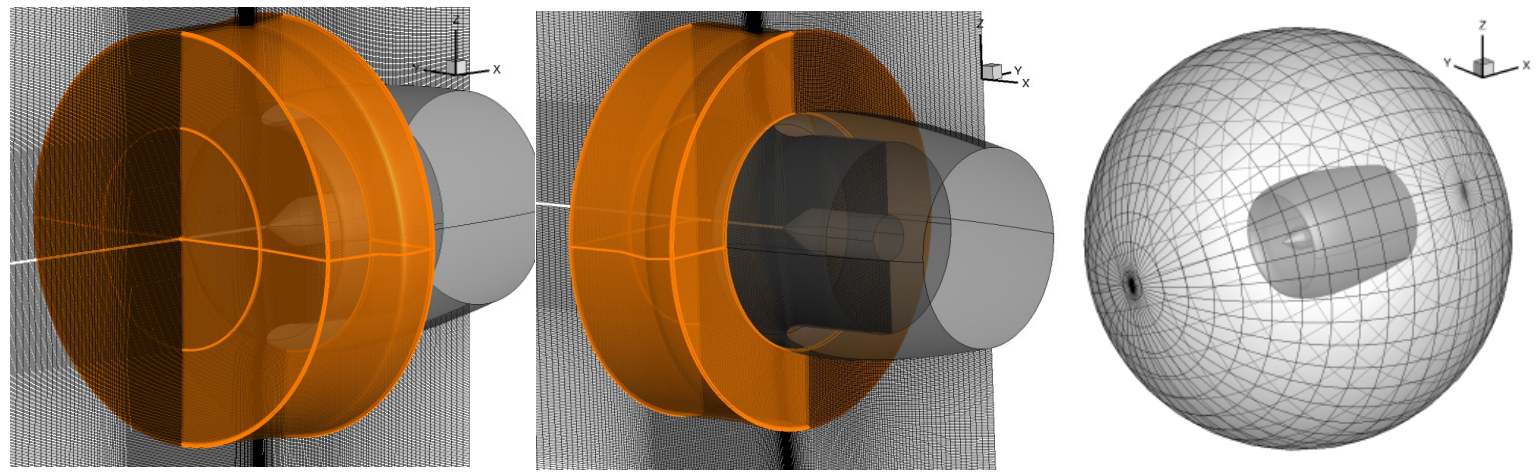

Fig. 7 Control surfaces for Kirchhoff integral (left) and observer surface for far-field directivity (right).

\section{Main results}

\section{A. Unsteady aerodynamics}

In the present extended abstract, aerodynamic results are mainly focused on the distortion case. Typical uRANS $360^{\circ}$ snapshots are shown in Fig. 8, in terms of axial velocity, showing a fully heterogeneous field with an expected local flow acceleration when the blade is going downward. These solutions (top) are found to be in a quite good agreement with those from Airbus (bottom) obtained with elsA code too, but considering the full annulus geometry. Basic analyzes of axial velocity field over the distortion map are addressed in Fig. 9, showing a largely dominant spatial harmonic with circumferential order equal to 1 (resulting to the fact that the shape of the profiles are almost sinusoidal). Consequently, expected dominant Tyler \& Sofrin interaction modes (close to the fan) should verify:

$$
m=n B-k V \pm 1
$$
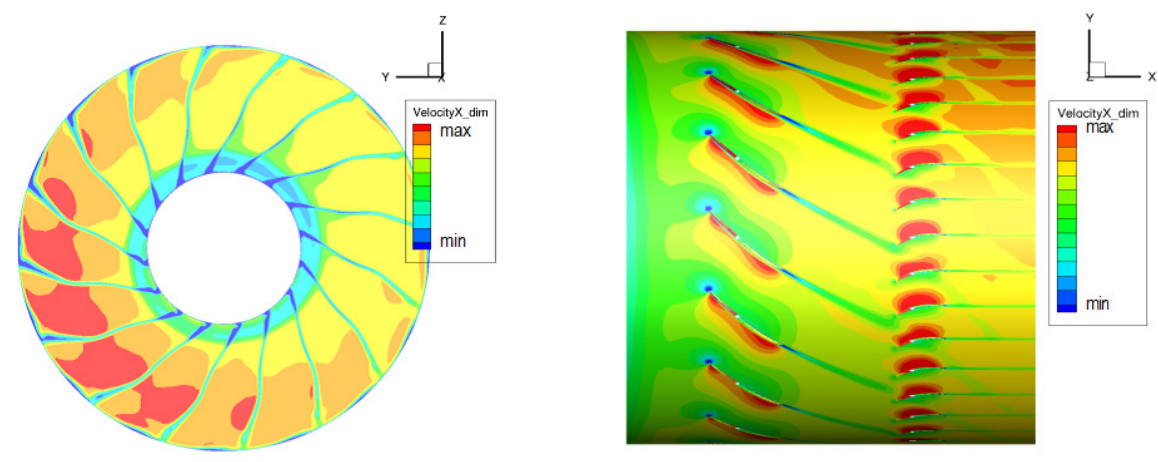

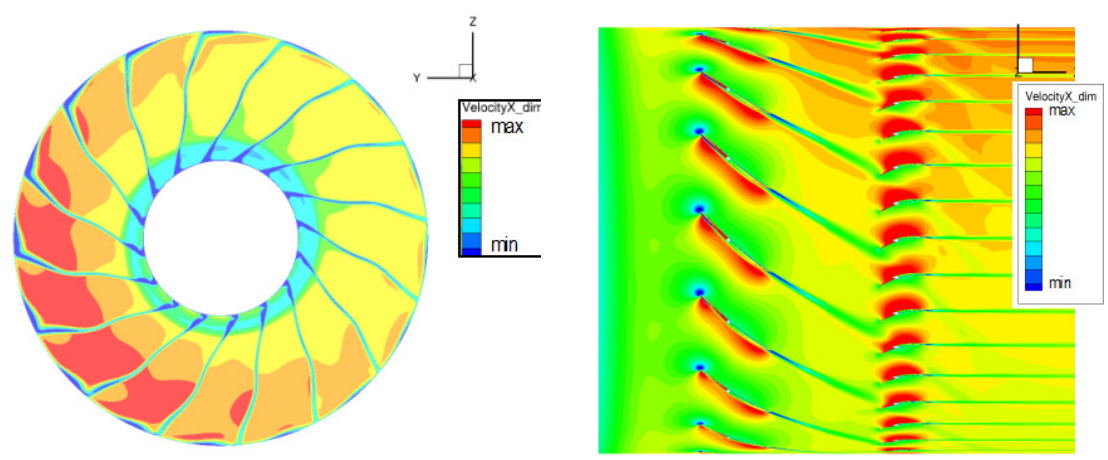

Fig. 8 Axial velocity snapshots issued from $360^{\circ}$ uRANS calculations: axial cut at $x=-0.5 \mathrm{~m}$ (left) and cylindrical cut (blade going upward) at $r=1 \mathrm{~m}$ (right) — ONERA (top) and Airbus (bottom) solutions.
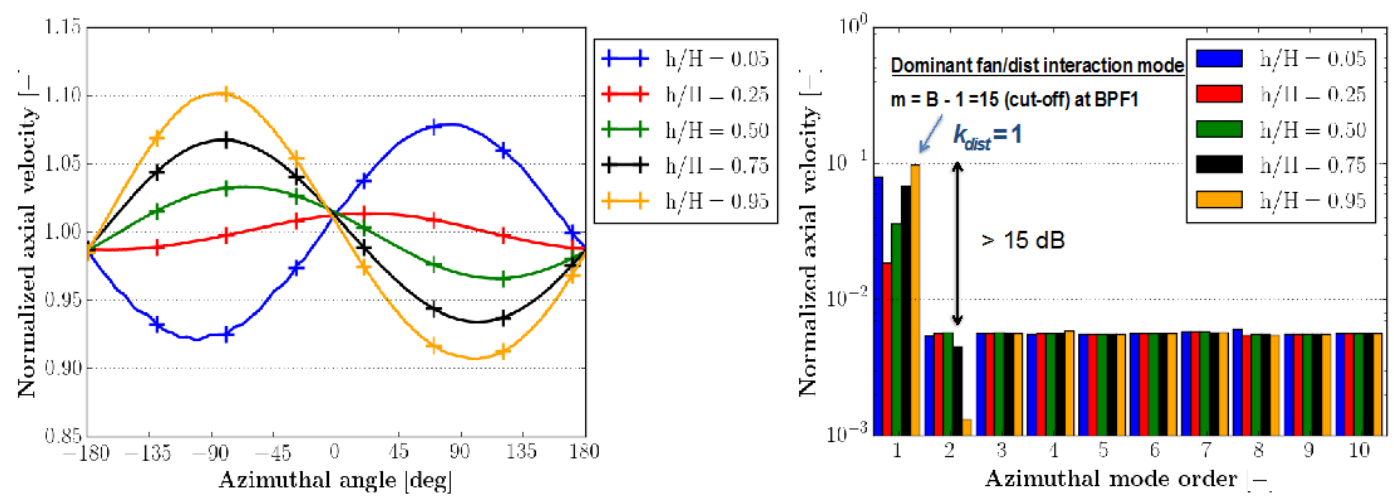

Fig. 9 Azimuthal profiles (left) and spatial harmonics (right) of axial velocity field extracted from the distortion map (provided by NLR) at different radial stations.

\section{B. Acoustic fields: in-duct propagation and radiation by intake}

A comparison of angular mode spectra between baseline and distortion case is presented in Fig. 10 using a 40 $\mathrm{dB}$ dynamic range (in order to see all the tones and the background remaining modes too). SPL spectra of total contribution (rotor + stator sources), issued from FanNoise, are plotted for an observer located at the inlet casing. Expected energy re-distribution over the neighboring interaction mode orders (compared to the baseline case) is clearly observed for the distortion case almost following Eq. (2).
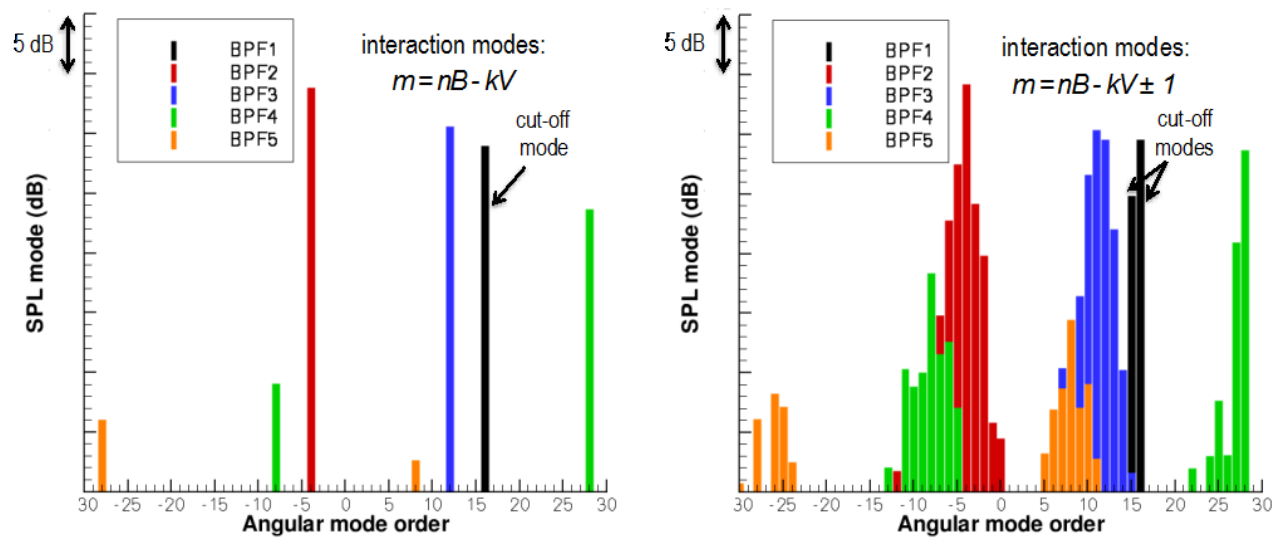

Fig. 10 Angular modes at the intake casing for baseline (left) and distortion case (right) 
SPL spectra in the inlet casing due to rotor sources contribution alone are plotted in Fig. 11 left. Under FanNoise assumptions, the $\mathrm{BPF}_{1}$ contribution in the intake is still found to be almost identical with or without distortion, due to the fact that most intense generated modes $(\mathrm{m}=16$ for baseline, and $\mathrm{m}=16,15$ for distortion case) are fully cutoff, with a dominant rotor-locked mode of same level in both cases (due to a roughly constant steady loading at the fan plane). The level of cut-on tones is increased in the presence of distortion, particularly for the higher harmonics, so that an increase of OASPL can be expected. The same analysis is performed in Fig. 11 right for the stator sources contribution at the bypass casing, showing a similar trend for higher tones $\left(\mathrm{BPF}_{4}\right.$ and $\left.\mathrm{BPF}_{5}\right)$, but a strong reduction of the emerging $\mathrm{BPF}_{2}$ tone, giving rise to a possible OASPL attenuation in the exhaust (as discussed in Section IV.C). .
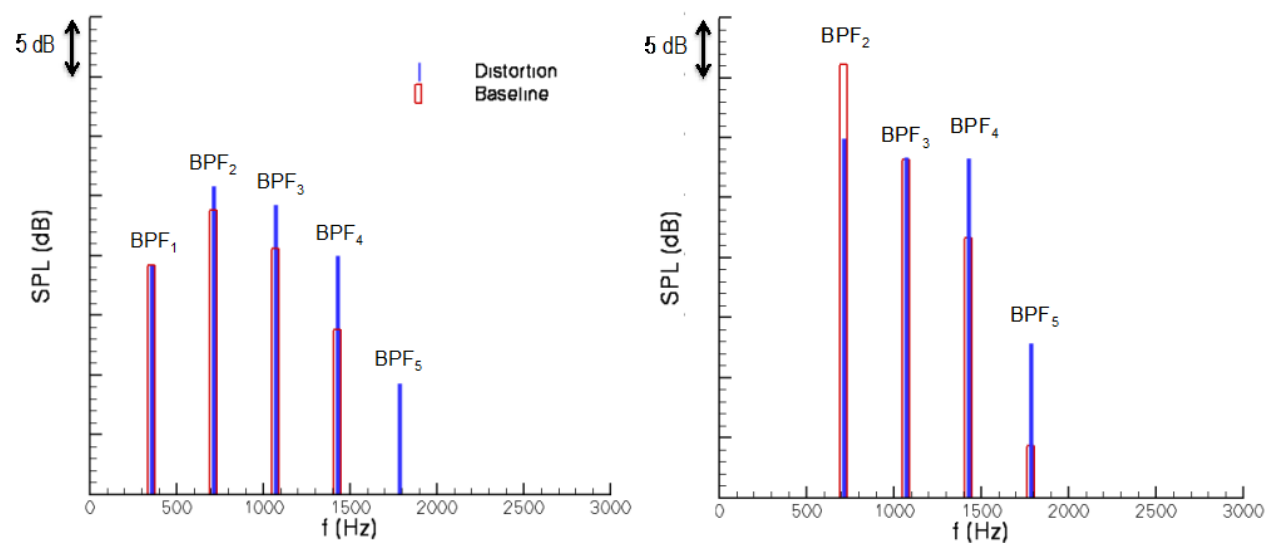

Fig. 11 Baseline vs. distortion SPL spectra at the intake casing (rotor sources only, left) and bypass casing (stator sources only, right)

Sound radiation obtained using modal amplitudes at the inlet exit plane is presented in Fig. 12 for the first three tones of the baseline configuration. Modes are assumed to be fully uncorrelated as usually done to better fit experimental data issued from aero-engine test rigs [20]. 3D directivity maps (Fig. 12, left) are then axisymmetric and the directivity peak (maximum radiation level in $\mathrm{XZ}$ plane) is shifted towards the sides as the spinning mode order is getting closer to the cut-off limit. At $\mathrm{BPF}_{1}$, the sound is mainly radiating on the side at $90^{\circ}$ (see Fig. 12 , right), but because the rotor-locked mode $(m=16)$ is highly cut-off at this regime, the maximum level is found to be largely below the other tones, for which $\mathrm{BPF}_{2}$ and $\mathrm{BPF}_{3}$ are dominant.
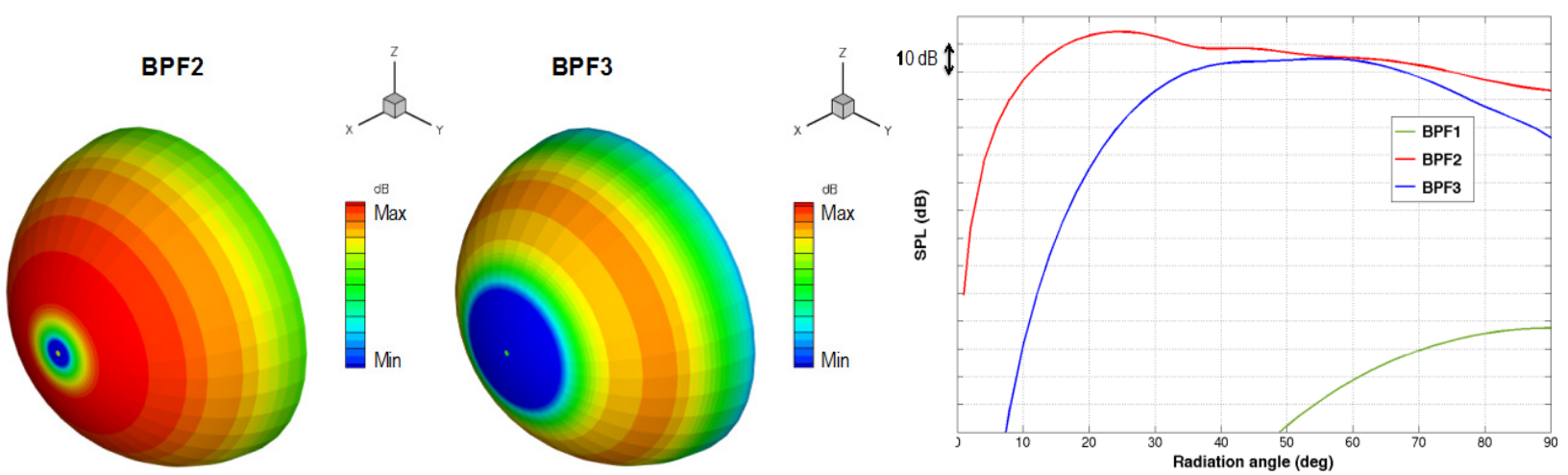

Fig. 12 SPL (dB) spherical maps (left) and directivity patterns (right) for the baseline case at $10 \mathrm{~m}$ from inlet

The last part of this section is devoted to the CAA predictions in terms of direct near-field and extrapolated farfield tone noise radiation for the distortion case. Real part of pressure harmonics and SPL maps of radiated sound field issued from direct $\mathrm{CAA}$ simulation and obtained for $\mathrm{BPF}_{1}-\mathrm{BPF}_{3}$ are presented in Fig. 13 and Fig. 14, 
respectively. The directivity patterns related to the $\mathrm{BPF}_{1}$ (theoretically cut-off at approach OP, even with inflow distortion) exhibit distinct lobes towards about $45^{\circ}$ direction with significant levels associated to unexpected loworder spinning mode orders (which are cut-on). Indeed, circumferential mode spectra assessed in the intake (not addressed here but discussed in the final paper) have revealed a dominant rotor-locked mode $\mathrm{m}=16$ (cut-off) close to the fan, but the emergence of energetic low-order modes too, as getting closer to the exit section. In Fig. 13, much more intense radiation patterns can be observed at $\mathrm{BPF}_{2}$, and almost no sound is found to radiate in the axis direction, which is a good accordance with Tyler \& Sofrin theory. SPL patterns plotted in Fig. 14, are confirming a dominant $\mathrm{BPF}_{2}$ tone but also a non-negligible contribution from the $\mathrm{BPF}_{1}$. Predictions relative to BPF2 and BPF3 are rather similar in terms of shape to those obtained by other partners in the framework of ASPIRE project, but significant level deviations can be observed when comparing 1D SPL directivity plots. In Fig. 14, the strong level attenuation in the farfield direction is simply due to the numerical dissipation effect when getting out of the refined area of the CAA grid. A validation of acoustic propagation from intake to far-field is proposed in Section $\mathrm{C}$ by controling the sound power balance.
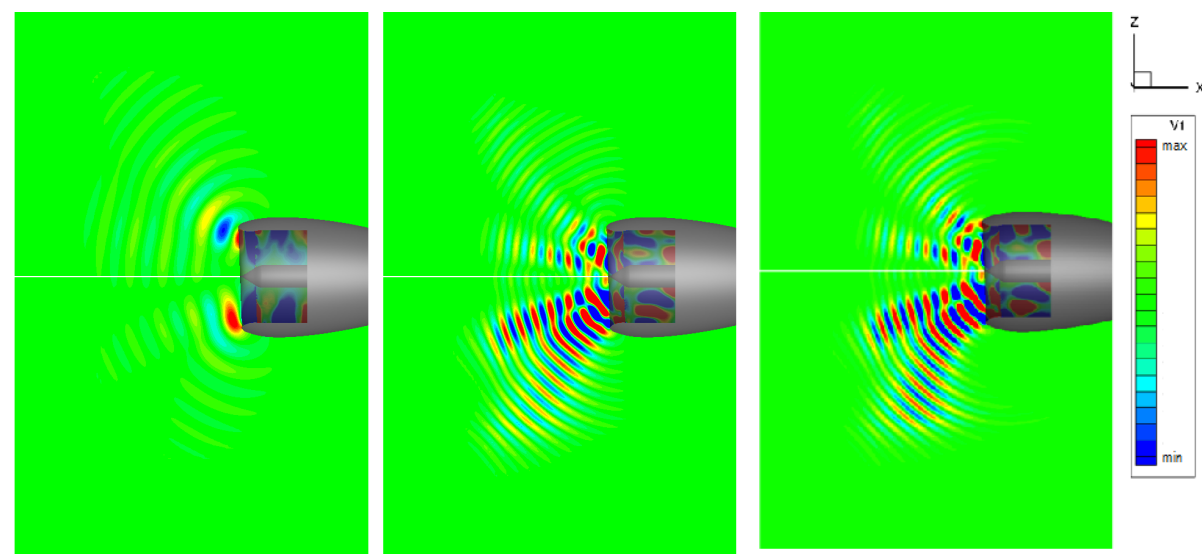

Fig. 13 Real part of near-field pressure harmonics $(\mathrm{Pa})$ at $\mathrm{BPF}_{1}$ (left), $\mathrm{BPF}_{2}$ (middle) and $\mathrm{BPF}_{3}$ (right).
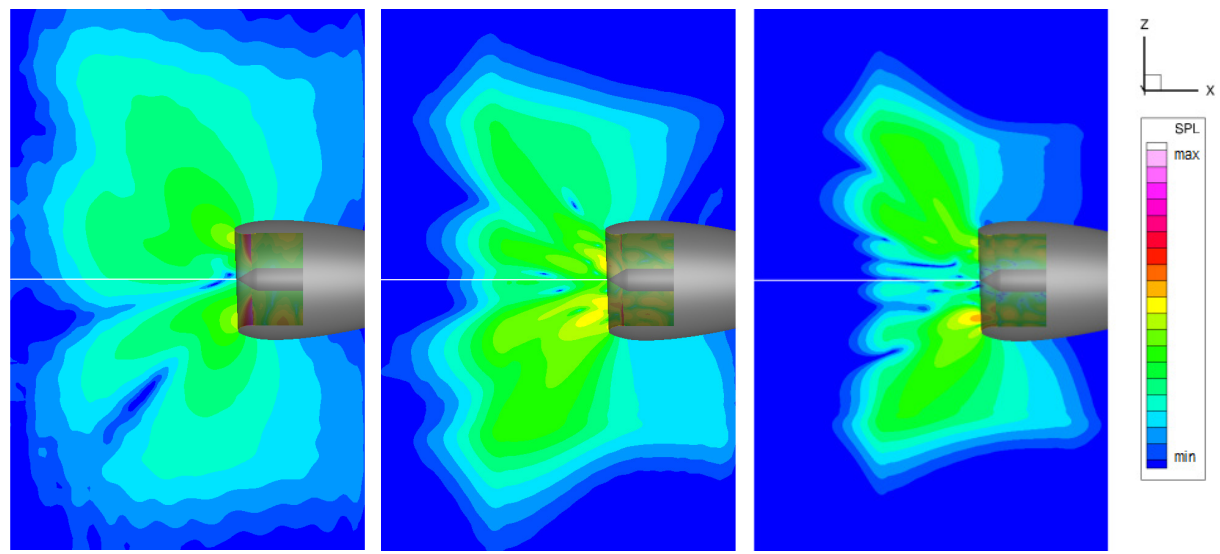

Fig. 14 SPL maps of near-field pressure $(\mathrm{dB})$ at $\mathrm{BPF}_{1}$ (left), $\mathrm{BPF}_{2}$ (middle) and $\mathrm{BPF}_{3}$ (right).

Predicted SPL spherical maps (front views) issued from CAA/Kirchhoff coupling are plotted in Fig. 15 for the three first tones, revealing inhomogeneous patterns in all directions, but mostly along the polar arcs (excepted for $\mathrm{BPF}_{1}$ ). Although this inhomogeneity is partly due to the asymmetric inflow in the intake region and to the dropped inlet, they might be due also to the presence of non-physical residual circumferential modes including a few modes of same order with opposite sign and responsible of a standing wave ratio in the azimuthal direction. This is particularly true for the non-converged $\mathrm{CFD}$ input at $\mathrm{BPF}_{1}$. However, spherical maps related to $\mathrm{BPF}_{2}$ and $\mathrm{BPF}_{3}$ exhibit more axisymmetric patterns, as shown by numerical predictions obtained by DLR using a time-harmonic balance method in their CFD simulations [4].. Nevertheless, assuming such complex 3D behaviors are relevant, they show in Fig. 16 strong variations of maximum radiation between flyover (mostly for $\mathrm{BPF}_{2}$ ) and sky (mostly for 
$\mathrm{BPF}_{3}$ ) directions. $\theta$ is the angle the meridian plane, $0^{\circ}$ and $180^{\circ}$ being respectively in the upstream and downstream directions. As also observed in this figure, the directivity shapes in dotted lines provided by the semi-analytical solution (for baseline case) discussed in Section III.B are quite consistent with the CAA solutions (for distortion case), with rather close location of dominant lobes.
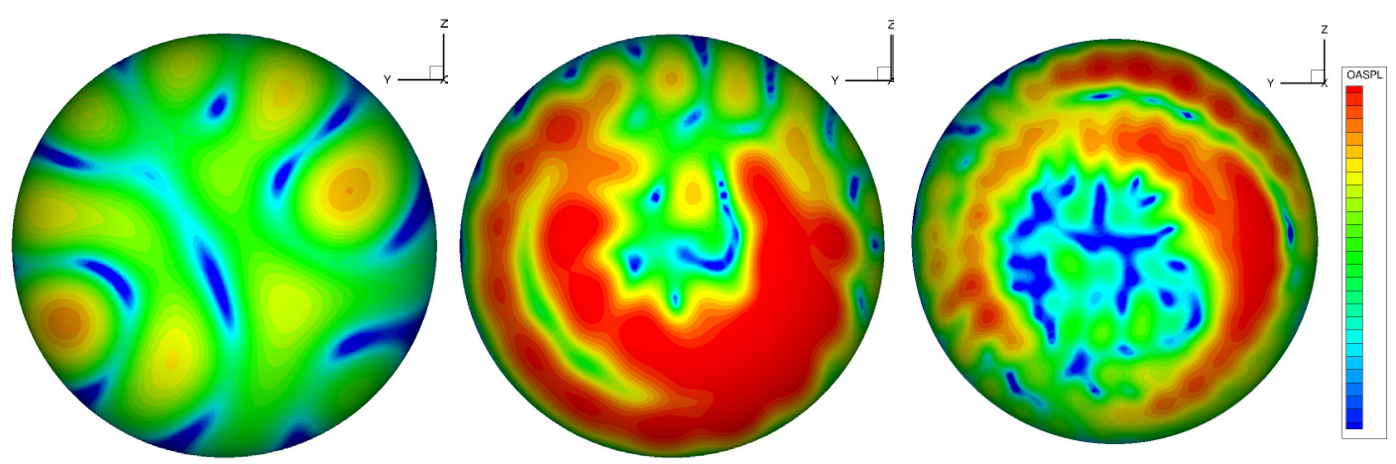

Fig. 15 Front views of $\operatorname{SPL}(d B)$ spherical maps at $r_{o b s}=100 \mathrm{~m}$ for $B P F_{1}$ (left), $B P F_{2}$ (middle) and $B P F_{3}$ (right).
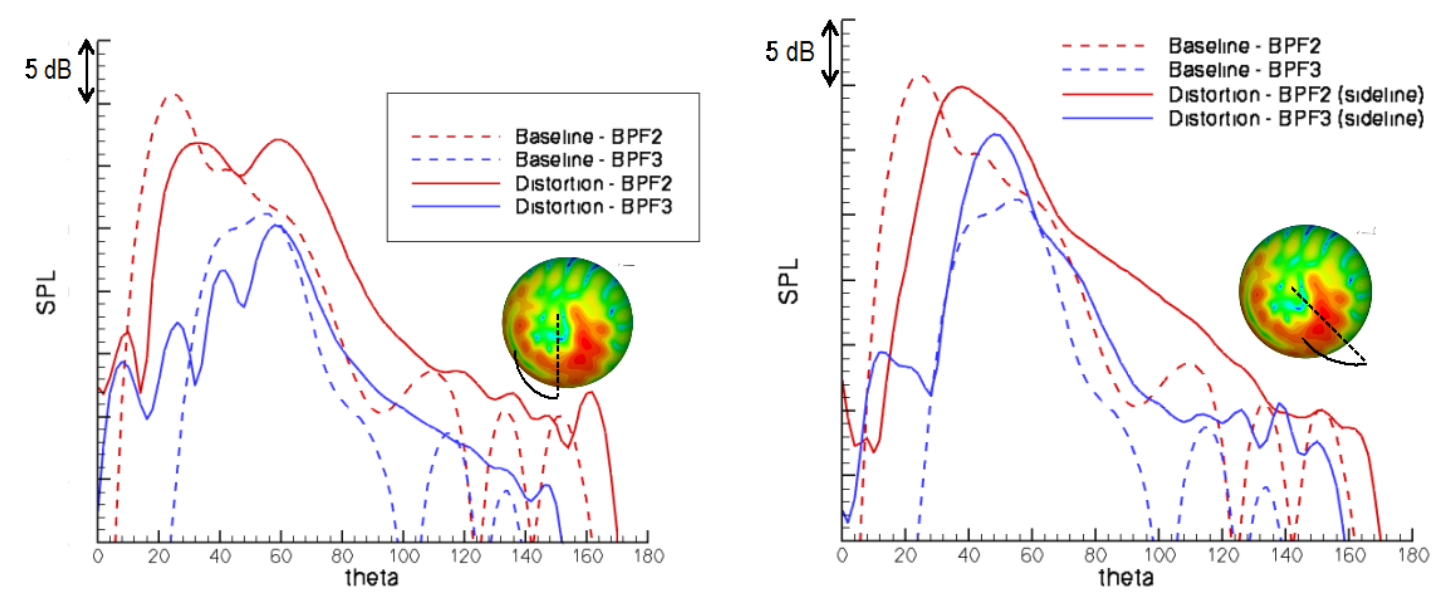

Fig. 16 Comparisons of far-field SPL directivities issued from baseline case (CFD+FWH, dashed lines) and distortion case (CFD+CAA, thick lines): flyover scanning (left) and sideline scanning (right).

\section{Sound power balance with highlights of distortion effects}

The assessment and analysis of in-duct (intake) and radiated sound power spectra obtained from the two methods presented in Section III (acoustic analogies and CAA) is proposed in this last Section. It is deduced from acoustic intensity following the well-known Cantrell and Hart's formulation [22][15] valid for irrotational flows. In-duct acoustic power is directly obtained by integrating the acoustic intensity over a cross-section of the intake. The radiated sound power can be easily assessed by integrating the intensity (derived from Cantrell an Hart) over a spherical surface (Fig. 7, right) and applying a suited form involving only the acoustic pressure as done in Ref. [23]. Axial evolution of the PWL spectrum along the intake is plotted in Fig. 17 (left) and balance between intake power (near the nacelle exit) and radiated power is depicted in 7 (right) for the inflow distortion case. An almost perfect conservation of the acoustic power along the axial direction is observed for the cut-on tones, which is a good point, whereas a strong attenuation of the PWL associated to the cut-off rotor-locked mode is clearly highlighted. However, the PWL of $\mathrm{BPF}_{1}$ is not decreasing anymore beyond a certain distance, and a non-expected plateau with significant level can be observed. It is due to the contribution of residual cut-on modes $(|\mathrm{m}| \leq 6)$ attributed to a nonfully converged CFD solution (indeed, more revolutions of the CFD computation are still required to decrease the residual energy of unphysical modes significant at the cut-off tone). Anyway, a perfect balance between intake and radiated power is shown in Fig. 17 right, for all considered frequencies, proving the non dissipative behavior of the 
present CFD/CAA coupling for acoustic propagation, as well as the accurate CAA/Kirchhoff coupling used for far field extrapolation The domination of $\mathrm{BPF}_{2}$ and $\mathrm{BPF}_{3}$ tones previously observed on SPL maps is recovered again.
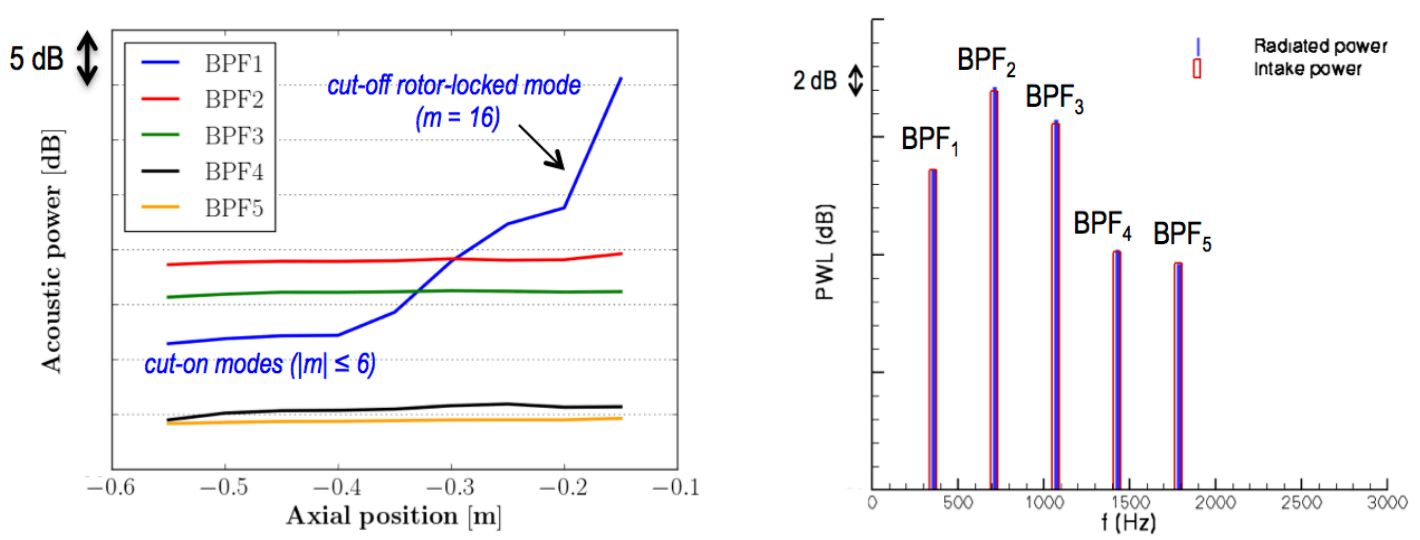

Fig. 17 Evolution of PWL spectrum along axial position of the intake (left) and balance between intake power (at $x=-0.5 \mathrm{~m}$ ) and radiated power (right).

Finally, PWL spectra obtained using the CFD data inputs with inflow distortion are compared to the baseline case in Fig. 18. The total contribution due to both rotor and stator sources are plotted in the intake and in the bypass, in Fig. 18 left and right, respectively. Regarding to elsA/FanNoise predictions, the inflow distortion effect on the harmonic overall power level, responsible to additional modes but associated with a re-distribution of acoustic energy too (as seen in Fig. 10), is traduced by an increase of $+1.5 \mathrm{~dB}$, upstream, and a quite noticeable decrease of $-3.4 \mathrm{~dB}$, downstream. The PWL spectra assessed by FanNoise are found to be in a fairly good agreement with those issued from CAA, so that the present distortion effects on sound power are expected to be confident.
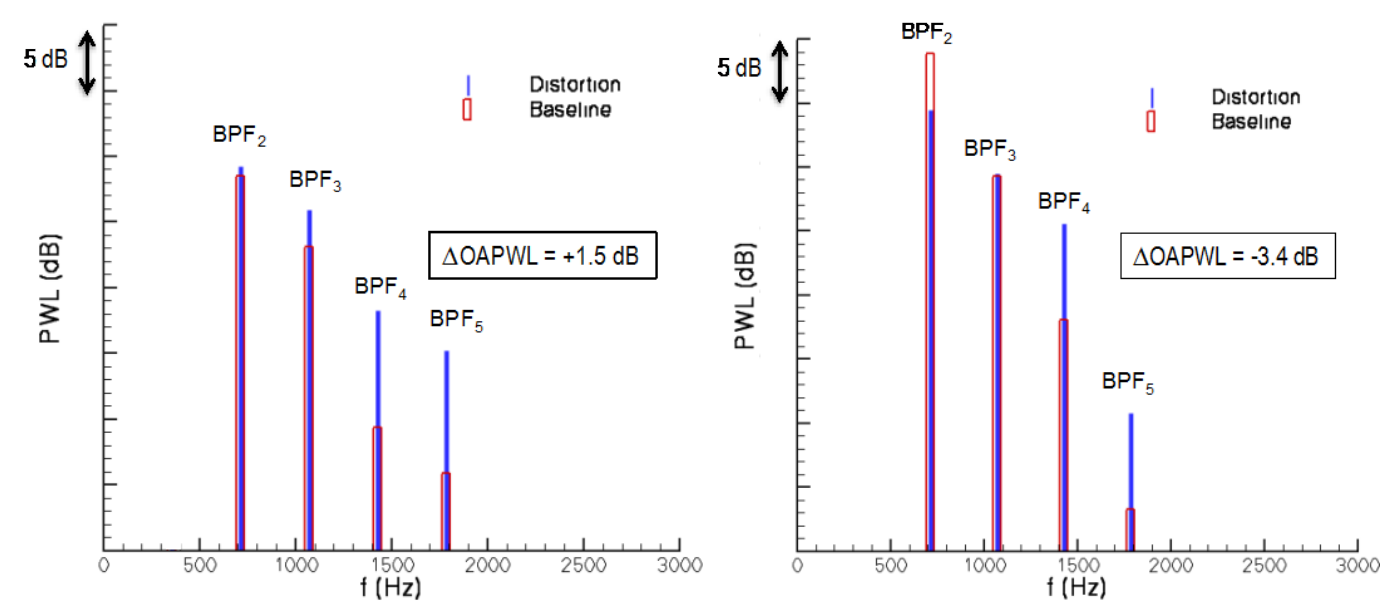

Fig. 18 Baseline vs. distortion PWL spectra due to rotor+stator sources in the intake (left) and bypass (right).

\section{Conclusion}

A CFD/CAA coupling using NRI technique with ONERA codes elsA and sAbrinA has been applied for the first time on a full-scale UHBR engine configuration including a 3D dropped intake with inflow distortion. Sound radiation by the intake has been fully assessed in terms of direct CAA near-field solution and far-field prediction using Kirchhoff extrapolation. Numerical solutions have been compared to more basic predictions based on a FWH analogy (adopting Goldstein's formulation valid for annular duct and uniform mean flow problem), requiring blade/vane harmonic loadings provided by uRANS as inputs, and performed on baseline and distortion cases. 
The present uRANS simulations are restricted to the internal flow by considering a semi-infinite annulus fan/OGV stage, and a distortion map issued from a CFD partner's solution (kindly shared by NLR) has been successfully traduced as a suited boundary condition in the code $e l s A$, providing unsteady fields almost identical to the full annulus calculation solution obtained by Airbus (with els $A$ code too). Furthermore, uRANS prescribed outputs over the NRI volume is injected in terms of harmonic disturbances (applied to the conservative variables) in the time-domain CAA solver, which facilitates the data transfer and speeds up the CAA convergence, by focusing on $\mathrm{BPF}_{1}$ to $\mathrm{BPF}_{5}$ tones.

Since the BPF tone is found to be cut-off at approach OP even in the presence of distortion, the over-estimated radiated SPL issued from the CFD/CAA is actually due to a non-fully converged uRANS solution. Indeed, more revolutions are still required to decrease the residual energy of unphysical modes (significant at the cut-off tone). This point will be more discussed in the final paper.

Nevertheless, a fairly good agreement has been obtained between CAA-based and FWH-based solutions with inflow distortion, expected to be relevant for cut-on tones $\left(\mathrm{BPF}_{2}\right.$ to $\left.\mathrm{BPF}_{5}\right)$, and giving rise to very close sound power levels in the intake. Moreover, a perfect balance between in-duct and radiated PWL has been verified, giving credit to our numerical methodology, from intake propagation up to far-field radiation. Regarding to those predictions, the main distortion effects are found to be responsible for an increase of about 1.5 dB OAPWL in the upstream direction, and a surprising reduction of more than $3 \mathrm{~dB}$ in the bypass duct.

\section{Acknowledgments}

This project has received funding from the Clean Sky 2 Joint Undertaking under the European Union's Horizon 2020 research and innovation program under grant agreement No 681856-2 - ASPIRE.

\section{References}

[1] Winkler, J., Reimann, C. A., Reba, R., Gilson, J., Turbofan Inlet Distortion Noise Prediction with a Hybrid CFD-CAA Approach, 20th AIAA/CEAS Aeroacoustics Conference, Atlanta (USA), (2014).

[2] Doherty, M., Namgoong, H., Impact of Intake Distortion on Fan Noise Propagation and Generation, 22nd AIAA/CEAS Aeroacoustics Conference, Lyon (France), (2016).

[3] Daroukh, M., Gourdain, N., Moreau, S., Boussuge, J. F., Sensiau, C., Impact of Inlet Distortion on Fan Tonal Noise, 12th European Conference on Turbomachinery Fluid Dynamics \& Thermodynamics, ETC12, Stockholm (Sweden), (2017).

[4] Guérin, S. Holewa, A., Fan tonal noise from aircraft aeroengines with short intake: A study at approach, International Journal of Aeroacoustics, (2018), DOI: 10.1177/1475472X18789001.

[5] Laban, M., Kok, J. C., and Brouwer, H., CFD/CAA Analysis of UHBR Engine Tonal Noise, 24th AIAA/CEAS Aeroacoustics Conference, Atlanta (USA), (2018).

[6] Polacsek, C., Chélius, A., Daroukh, M., François, B., Barrier, R., Tone Noise Prediction of a Full-Scale UHBR Engine with Short Inlet and Inflow Distortion, ICSV25 Conference Proceedings, Hiroshima (Japan), (2018).

[7] Cambier, L., Heib, S., Plot, S., The Onera elsA CFD Software: Input from Research and Feedback from Industry, Mechanics \& Industry, 14(3), pp. 159-174, (2013).

[8] Guenanff, R., Couplage instationnaire Navier-Stokes/Euler pour la génération et le rayonnement des sources de bruit aérodynamique, Ph.D. thesis, Université Rennes I, 2004, No 3138.

[9] Redonnet, S., Manoha, E., and Sagaut, P., "Numerical Simulations of Propagation of Small Perturbations Interacting with Flows and Solid Bodies," Proceedings of 7th AIAA/CEAS Aeroacoustics Conference, 2001.

[10] Redonnet, S., Simulation de la propagation acoustique en présence d'écoulements quelconques et de structures solides, par résolution numérique des équations d'Euler, Ph.D. thesis, Université Bordeaux I, 2001.

[11] Redonnet, S., Desquesnes, G., Manoha, E., and Parzini, C., "Numerical Study of Acoustic Installation Effects with a Computational Aeroacoustics Method", AIAA Journal, Vol. 48, No. 5, pp. 929-937, (2010).

[12] Goldstein, M. E., Aeroacoustics, McGraw-Hill, New York, (1976).

[13] Bonneau, V., Polacsek, C., Barrier, R., Léwy, S., Roux, J. M., and Gervais, Y., Tonal Noise Prediction of a Turbofan with Heterogeneous Stator and Bifurcations, AIAA Journal, 53(11), (2015).

[14] Laban, M., Kok, J. C., and Brouwer, H., CFD/CAA Analysis of UHBR Engine Tonal Noise, 24th AIAA/CEAS Aeroacoustics Conference, Atlanta (USA), (2018).

[15] Léwy, Polacsek, C., Barrier, R., Analytical and Numerical Prediction of Harmonic Sound Power in the Inlet of Aeroengines with Emphasis on Transonic Rotation Speeds, Journal of Sound and Vibration, 333, pp. 7165-7182, (2014).

[16] Guérin, S., Far Field Radiation of Induct-Cutoff Pressure Waves, 23rd AIAA/CEAS Aeroacoustics Conference, Denver (USA), (2017). 
[17] Redonnet, S., Lockard, D. P., Khorrami, M. R., and Choudhari, M. M., The non-reflective interface - an innovative forcing technique for computational acoustic hybrid methods, Int. J. Numer. Meth. Fluids, 81 - 22-44. doi 10.1002/fld.4173, (2016).

[18] Chelius, A., Le Garrec, T., and Mincu, D.C., Open-Rotor Noise Assessment with CFD/CAA Chaining, AIAA Aviation, Dallas, TX, 21st AIAA/CEAS Aeroacoustics Conference, 2015.

[19] Tyler, J.M, Sofrin, T.G., Axial Flow Compressor Noise Studies, SAE Transactions, 70, 309-332, (1962).

[20] Reboul, G., Polacsek, C., Billonnet, G., Prediction of BPF Tones emitted by the Inlet of an Aero-engine Model using In-duct Angular Mode Spectrum Measurements, 20th AIAA/CEAS Aeroacoustics Conference, Atlanta (USA), (2014).

[21] Péron, S., Benoit, C., Landier, S., and Raud, P., "Cassiopee: CFD Advanced Set of Services in an Open Python Environment," 12th Symposium on Overset Composite Grids \& Solution Technology, Atlanta, GA, 6-9 October 2014.

[22] Cantrell R. H. and Hart R. W., Interaction between Sound and Flow in Acoustic Cavities : Mass, Momentum and Energy Considerations, Journal of Acoustic Society of America, Vol. 36, pp 696-706, 1964.

[23] Lewy, S. Computation of broadband noise radiated by a ducted fan in a uniform flow, International Journal of Acoustics and Vibration 8 (4), 211-218, (2003). 